\title{
False memories for shape activate the lateral occipital complex
}

\author{
Jessica M. Karanian and Scott D. Slotnick \\ Department of Psychology, Boston College, Chestnut Hill, Massachusetts 02467, USA
}

\begin{abstract}
Previous functional magnetic resonance imaging evidence has shown that false memories arise from higher-level conscious processing regions rather than lower-level sensory processing regions. In the present study, we assessed whether the lateral occipital complex (LOC) - a lower-level conscious shape processing region-was associated with false memories for shape. During encoding, participants viewed intact or scrambled colored abstract shapes. During retrieval, colored disks were presented and participants indicated whether the corresponding item was previously "intact" or "scrambled." False memories for shape ("intact"/scrambled > "scrambled"/scrambled) activated LOC, which indicates lower-level sensory processing regions can support false memory.
\end{abstract}

[Supplemental material is available for this article.]

Functional magnetic resonance imaging (fMRI) studies have investigated the neural basis of false memories-instances in which you remember something that never actually occurred. Such studies have demonstrated that activity associated with true memories for visual information is greater than activity associated with false memories for visual information in lower-level sensory processing regions, including Brodmann area (BA) 17 (i.e., V1) (Okado and Stark 2003; Stark et al. 2010; Dennis et al. 2014) and BA18 (Okado and Stark 2003; Stark et al. 2010; Dennis et al. 2012, 2014; Karanian and Slotnick 2014). Highlighting this apparent dissociation between true memory and false memory activity in the earliest visual cortical regions, false memory contrasts (e.g., false memory $>$ correct rejection) have not revealed memory-related activity in BA17/V1 (Heun et al. 2000; Cabeza et al. 2001; Hofer et al. 2007; Dennis et al. 2008, 2012, 2014; Marchewka et al. 2008; Stark et al. 2010; Gutchess and Schacter 2012; Iidaka et al. 2012; Karanian and Slotnick 2014). The same pattern of activity was also observed in motion processing cortex (MT+) (Karanian and Slotnick 2014). Specifically, we found that true memory for motion activated $\mathrm{MT}+$, whereas false memory for motion was associated with activity in language processing regions. Here, MT+ is considered a lower-level visual processing region, as it is retinotopic and just anterior to V4 (Slotnick and Yantis 2005). The preceding results have given rise to the current view that true memories, but not false memories, are underpinned by activity in lower-level sensory processing regions. In contrast, false memories have been associated with activity in higher-level conscious processing regions, including later visual regions, the prefrontal cortex, and language processing regions (e.g., Okado and Stark 2003; Slotnick and Schacter 2004; Dennis et al. 2012; Karanian and Slotnick 2014).

Of present interest, false memories, which reflect conscious processing, may not have activated BA17/V1 or MT+ due to nonconscious processing that occurs in these regions (Crick and Koch 1995; Tong 2003; Slotnick and Schacter 2004, 2006; Stark et al. 2010). The lateral occipital complex (LOC), another lower-level visual processing region that is retinotopic and lies im-

Corresponding author: jessicakaranian@gmail.com

Article is online at http://www.learnmem.org/cgi/doi/10.1101/lm.045765. 117. mediately inferior-posterior to MT+ (Sayres and Grill-Spector 2008), plays a critical role in the conscious processing of shape and object stimuli (Grill-Spector et al. 2000; Kourtzi and Kanwisher 2000; Deshpande et al. 2010; Karanian and Slotnick 2015; Cohen et al. 2017). Given its role in conscious processing, we predicted that false memory for shapes would activate LOCthe earliest sensory region in which holistic shape information is processed. If observed, this would challenge the predominant view that false memories are not associated with activity in lowerlevel sensory processing regions.

In the present study, we used an fMRI paradigm in which participants remembered intact shapes and scrambled shapes, and false memories for shape were defined as "intact" responses to previously scrambled shapes (Fig. 1). Although previous false memory studies have used stimuli such as abstract shapes (e.g., Slotnick and Schacter 2004) and objects (Dennis et al. 2012) that have been associated with activity in LOC, they have not assessed the functional role of LOC during false memory for shape information. The present study is novel in multiple ways. We included both intact shapes and scrambled shapes during the encoding phase such that LOC could be localized by contrasting these item types. Then, it was assessed whether false memory-related activity was observed in this region during the retrieval phase. The present task is also the first to ask participants to retrieve shape-specific information when compared with previous studies where participants made "old"-"new" recognition judgments. That is, during the retrieval phase, participants in the present study were cued with one item feature (i.e., color) and asked to recall whether the corresponding item was previously "intact" or "scrambled." This allowed us to directly assess the functional role of LOC during the construction of shape-specific false memories.

Fourteen undergraduate students participated in the study (6 females, age range 19-22 yr). During fMRI, participants completed nine memory runs. During the encoding phase of each run, 16

\footnotetext{
C) 2017 Karanian and Slotnick This article is distributed exclusively by Cold Spring Harbor Laboratory Press for the first 12 months after the full-issue publication date (see http://learnmem.cshlp.org/site/misc/terms.xhtml). After 12 months, it is available under a Creative Commons License (AttributionNonCommercial 4.0 International), as described at http://creativecommons. org/licenses/by-nc/4.0/.
} 


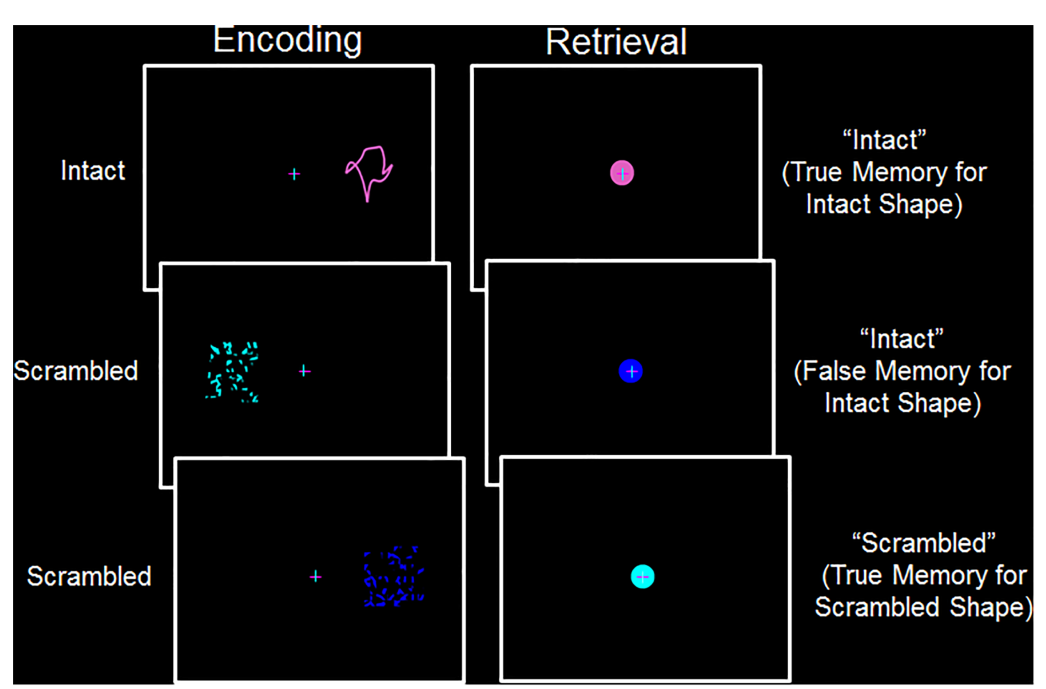

Figure 1. During encoding, uniquely colored intact or scrambled shapes were presented to the left or right of fixation. During retrieval, colored disks corresponding to the previously studied shapes were presented at fixation and participants classified each of the corresponding shapes as previously "intact" or "scrambled" (illustrative responses and item types are shown to the right).

uniquely colored intact or scrambled shapes were presented in the left or right visual field (Fig. 1, left). Each scrambled shape was created by superimposing a $10 \times 10$ grid over the bounding box of an intact shape and then each pixel was reassigned to a random location within the grid. Each shape was presented for $2.5 \mathrm{sec}$ with an inter-trial interval of $3.0 \mathrm{sec}$. Shape sets were randomized and presented sequentially five times. Participants were instructed to always maintain fixation and to remember each shape and its spatial location. During the retrieval phase of each run, 16 colored disks corresponding to the previously studied shapes were presented in random order at fixation (Fig. 1, right). Each disk was presented for $3.5 \mathrm{sec}$ with an inter-trial interval of 7-10 sec. Participants classified the shape corresponding to the colored disk as previously "intact" or "scrambled" in the "left" or "right" visual field via button presses.

Data were acquired using a Siemens $3 \mathrm{~T}$ Trio Scanner with a 12-channel head coil. Functional images were acquired with an echo planar imaging sequence. Anatomic images were acquired with a magnetized prepared rapid gradient echo sequence. Brain Voyager QX (Brain Innovation B.V.) was used to conduct the analysis. Standard preprocessing was conducted followed by a randomeffect general linear model analysis. An individual voxel threshold of $P<0.001$ was enforced for all comparisons (Slotnick and Schacter 2004), whole-brain false discovery rate corrected for multiple comparisons to $P<0.05$. Activations were projected onto a representative inflated cortical surface for display purposes following the procedure of Slotnick (2005). Event-related activation timecourses were extracted from LOC (i.e., voxels within a 7-mm cube centered at each selected coordinate) within the time range of -2 to $12 \mathrm{sec}$ after stimulus onset (baseline corrected from -2 to $0 \mathrm{sec}$ ). Statistical analysis was based on the peak amplitude of activity from 6 to $8 \mathrm{sec}$ after stimulus onset, the expected maximum of the hemodynamic response, to avoid violation of independence. Additional participant, procedure, and MRI acquisition and analysis details can be found in the Supplemental Material.

We isolated shape processing activity by contrasting encoding/perception of intact shapes and encoding/perception of scrambled shapes (intact shape encoding $>$ scrambled shape encoding). As activity associated with shape encoding/perception was widespread (Fig. 2, in yellow), LOC was anatomically localized to the lateral aspect of the occipital lobe (Kourtzi and Kanwisher 2000; Karanian and Slotnick 2015).

To test for sensory-specific reinstatement of encoding-related activity during true memory for shape (i.e., hits > misses), we ran a conjunction of shape processing and true memory for shape (intact shape encoding $>$ scrambled shape encoding) ก ("intact"/intact > "scrambled"/intact), which revealed activity in LOC (Fig. 2, top, in orange). The analogous conjunction for false memory (intact shape encoding $>$ scrambled shape encoding) ก ("intact"/scrambled > "scrambled"/ scrambled) also revealed activity in LOC (Fig. 2, middle, in orange). It is noteworthy that more anterior regions of LOC were associated with both true and false memories, while more posterior regions were associated with only true memories, which may reflect functional processing differences within LOC subregions (Karanian and Slotnick 2015).

To assess whether there were any regions of overlapping activity, we conducted a triple conjunction of shape processing, true memory for shape, and false memory for shape (intact shape encoding $>$ scrambled shape encoding) $\cap$ ("intact"/intact $>$ "scrambled"/intact) $\cap$ ("intact"/scrambled > "scrambled"/scrambled). This conjunction produced one small activation in LOC (centered at Talairach coordinate $x=36, y=-69, z=10$; spatial extent $=27 \mathrm{~mm}^{3}$; Fig. 3 , bottom, in orange).

We also ran a conjunction of shape processing and true memory versus false memory (intact shape encoding $>$ scrambled shape encoding) $\cap($ ("intact"/intact > "scrambled"/intact) $>$ ("intact"/ scrambled > "scrambled"/scrambled)). This produced activity in several regions of LOC (Fig. 3), which is similar to the greater true memory than false memory activity that has been observed in other lower-level sensory processing regions (i.e., BA17/V1, MT+).

The present study investigated whether false memories could activate lower-level sensory processing regions under particular stimulus conditions. Specifically, we hypothesized that false memory for shape may activate LOC, given its relatively conscious role in visual processing (e.g., Ungerleider and Mishkin 1982; Karanian and Slotnick 2015; Cohen et al. 2017). Consistent with our hypothesis, we found that false memories for shape activated LOC.

The present results are in direct contrast with what we observed in our previous study in which participants remembered whether items were previously moving or previously stationary (Karanian and Slotnick 2014). Specifically, we found that true memory for motion, but not false memory for motion, activated motion processing region, MT+ (Karanian and Slotnick 2014). To assess the apparent dichotomy between LOC and MT+, we extracted activity from the LOC activation associated with true memory and false memory in the present study and compared this activation profile to the activation profile from MT+ in our previous study (Karanian and Slotnick 2014). There was a significant region (MT+, LOC) by memory type (true, false) interaction $(P<0.05)$, which indicates that the involvement of sensory cortical regions during false memory is dependent on stimulus type. Specifically, the magnitudes of true memory and false memory activity did not significantly differ in LOC $(P>0.20)$, but the magnitude of true memory activity was greater than the magnitude of false memory activity in $\mathrm{MT}+(P<0.05)$. We propose that this region by memory type interaction reflects relatively nonconscious and conscious 


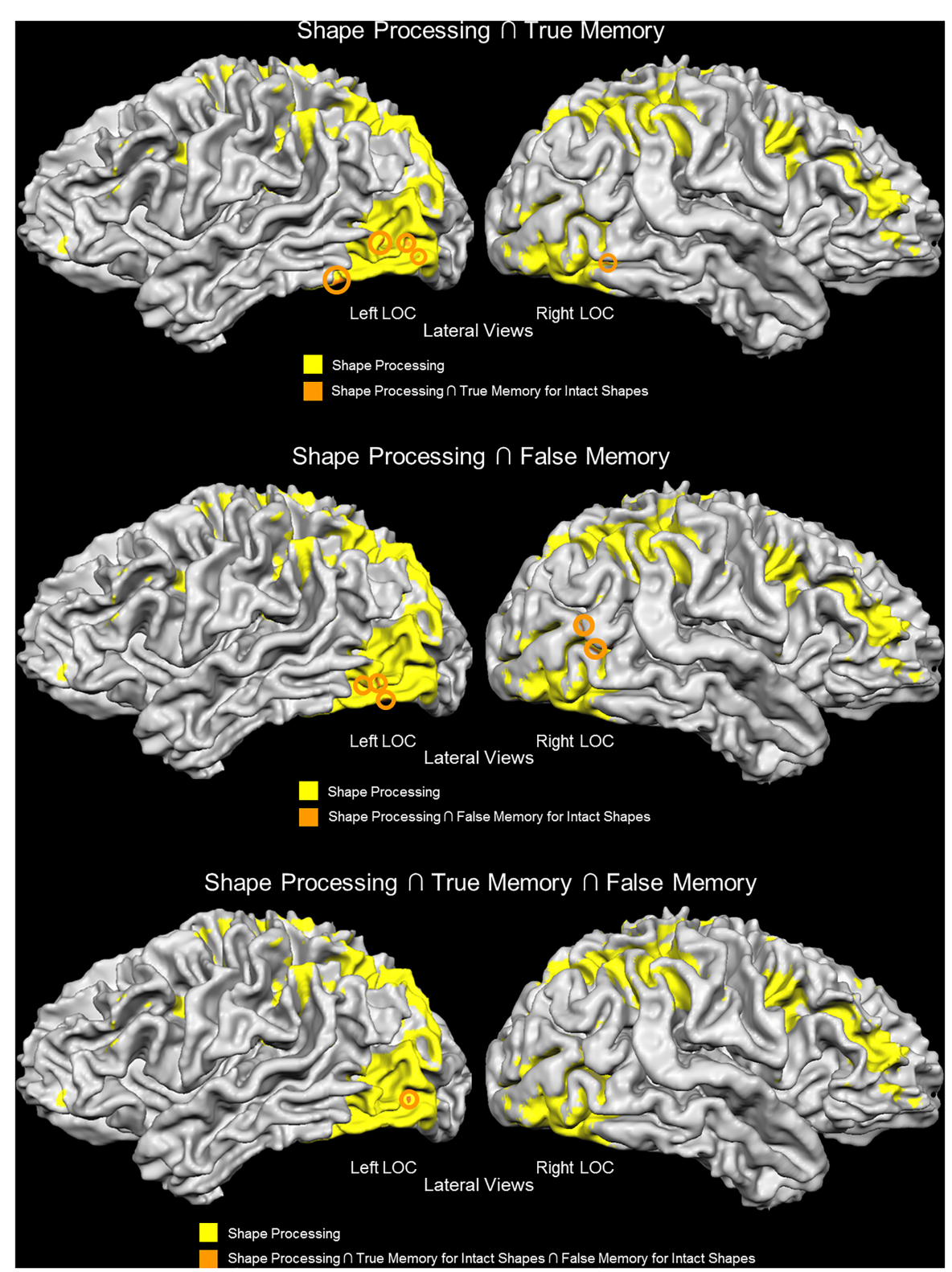

Figure 2. True memory and false memory activity in LOC. Shape processing activity is shown in yellow. (Top) activity associated with true memory for shape is shown in orange (lateral views; key at the bottom). (Middle) activity associated with false memory for shape is shown in orange (lateral views; key at the bottom). (Bottom) activity associated with both true memory and false memory is shown in orange (lateral views; key at bottom). Activations within LOC are circled.

er LOC activity during accurate than inaccurate memory for shapes (Karanian and Slotnick 2015). Thus, in light of this nonconscious and conscious processing dichotomy observed between MT+ and LOC, the differential pattern of true versus false memory activity likely stems from the distinct functional processing that occurs within these lower-level sensory processing regions.

Our findings are in opposition to the predominant view that false memories are not underpinned by activity in lower-level sensory processing regions. It is noteworthy that only three previous studies have reported false memoryrelated activity in BA17/V1; however, such false memory activity may not have reflected episodic memory activity due to confounds. In two of these studies (Slotnick and Schacter 2004; GaroffEaton et al. 2006), participants were presented with abstract shapes during the encoding phase. During the retrieval phase, old items, related items, and new items were presented, and participants classified each item as "old" or "new" (Slotnick and Schacter 2004) or "old," "similar," or "new" (Garoff-Eaton et al. 2006). False memory activity was isolated by contrasting "old"/related items and "new"/new items (Slotnick and Schacter 2004) or by contrasting "old"/related items and "old"/new items (GaroffEaton et al. 2006). Previous work has shown that related shapes, when compared with new shapes, produce increases in repetition priming-related activity within early visual regions (Slotnick and Schacter 2006; Thakral et al. 2017). Thus, the previously reported false memory-related activity in BA17/V1 in these two studies can be attributed to repetition priming. A third study (Okado and Stark 2003) used a paradigm in which audio words preceded either a picture of the word or a blank screen, which cued the participant to imagine an object that corresponded to the word. At retrieval, participants were presented old and new words and decided whether each word was previously paired with an object, imagined, or new. Okado and Stark

processing within MT+ and LOC, respectively. That is, MT+ is located within the "where" pathway, which is thought to mediate largely nonconscious visual processing (e.g., Ungerleider and Mishkin 1982; Goodale and Milner 1992). Furthermore, two recent studies indicate that MT+ plays a nonconscious role during memory for motion (Karanian and Slotnick 2014; Thakral and Slotnick 2014). In contrast, LOC is located within the "what" pathway, which is thought to be associated with conscious experience of shape/object recognition (Ungerleider and Mishkin 1982; Goodale and Milner 1992; Kourtzi and Kanwisher 2000). Highlighting its role in conscious processing, LOC activity has been correlated with behavioral performance during object recognition (e.g., Grill-Spector et al. 2000), and we recently found great-
(2003) contrasted false memory ("seen"/imagined) and correct rejections ("new"/new), which activated V1. However, since false memory was induced by imagery, and imagery can activate V1 (Slotnick et al. 2005), such activity may have reflected imagery.

Replicating previous work, we also found that true memory activity was greater than false memory activity in lower-level sensory cortex (i.e., LOC). These findings are consistent with the sensory reactivation framework, which stipulates that the original features/sensory information associated with an encoding experience will be reinstated at retrieval (e.g., Schacter et al. 1998; Wheeler et al. 2000; Gottfried et al. 2004; Slotnick 2009a,b; Slotnick and Thakral 2011; Karanian and Slotnick 2014, 2015). Thus, the differential sensory activity observed during true 


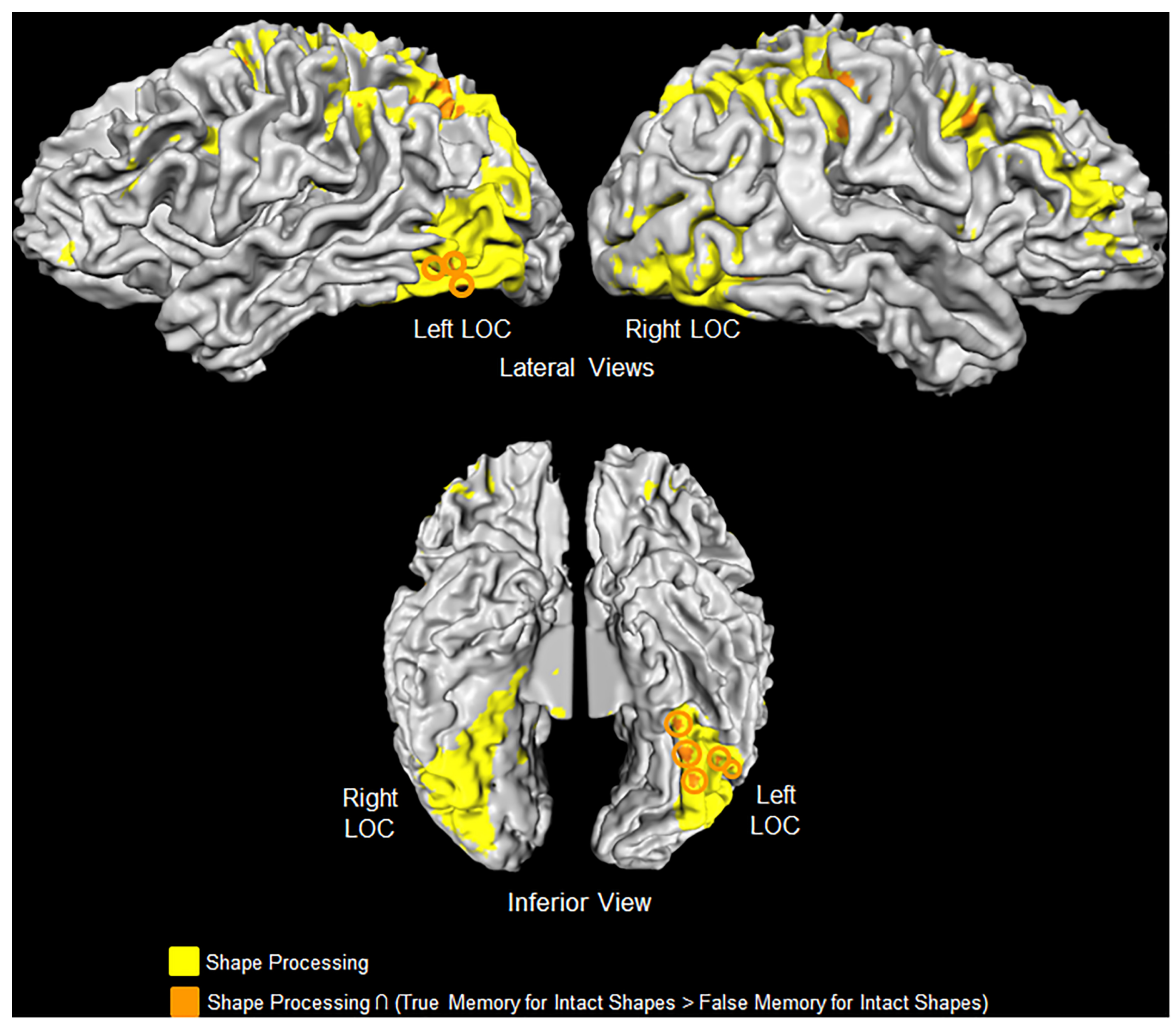

Figure 3. True memory versus false memory activity in LOC. Shape processing activity is shown in yellow. Activity associated with the conjunction of shape processing and (true memory for shape $>$ false memory for shape) is shown in orange (key at the bottom). Activations within LOC are circled.

memories versus false memories can be attributed to sensory reactivation, as only true memories are associated with the original encoding experience.

The present finding that true memory and false memory produced activity in lower-level sensory processing regions is consistent with behavioral findings that both true memory and false memory can be associated with detailed subjective memorial experience (e.g., Roediger and McDermott 1995; Payne et al. 1997; Lampinen et al. 1998). Related to this, the current results indicate that detailed subjective experience during false memories can be mediated by stimulus-specific activity in lower-level sensory processing regions. We also collected "remember" and "know" responses to characterize subjective experience, but it was necessary to collapse over these responses to gain adequate power. This is a limitation of the present study. Future work could investigate how such responses affect activity in lower-level sensory processing regions during true and false memories.

The present finding that false memory for shapes activates LOC suggests that lower-level sensory processing regions may underpin the construction of false memories under particular stimulus conditions. Future research will be needed to assess whether such effects are observed in other lower-level sensory processing regions within the ventral processing stream. For instance, we predict that false memory for color will activate color processing region V8. Another future line of research could use tasks that induce conscious processing in lower-level sensory processing regions, such as spatial memory tasks that have been shown to produce conscious processing in V1 (Thakral et al. 2013), to assess whether false memory can activate lower-level sensory processing regions under those task conditions. Critically, the present finding that false memories can activate lower-level sensory processing regions calls for a revision of the predominant view that only true memories activate these regions.

\section{Acknowledgments}

This work was supported by NSF grant BCS0745880.

\section{References}

Cabeza R, Rao SM, Wagner A, Mayer AR, Schacter DL. 2001. Can medial temporal lobe regions distinguish true from false? An event-related functional MRI study of veridical and illusory recognition memory. Proc Natl Acad Sci 98: 4805-4810.

Cohen MS, Cheng LY, Paller KA, Reber PJ. 2017. Lateral occipital complex activation associated with response confidence during forced-choice recognition of novel abstract kaleidoscope images. Poster presented at the Cognitive Neuroscience Society 24th Annual Meeting, San Francisco, CA.

Crick F, Koch C. 1995. Are we aware of neural activity in primary visual cortex? Nature 375: 121-123.

Dennis NA, Kim H, Cabeza R. 2008. Age-related differences in brain activity during true and false memory retrieval. J Cogn Neurosci 20: 1390-1402.

Dennis NA, Bowman CR, Vanderkar SN. 2012. True and phantom recollection: an fMRI investigation of similar and distinct neural correlates and connectivity. Neuroimage 59: 2982-2993.

Dennis NA, Johnson CE, Peterson KM. 2014. Neural correlates underlying true and false associative memories. Brain $\operatorname{Cogn}$ 88: 65-72.

Deshpande G, Hu X, Lacey S, Stilla R, Sathian K. 2010. Object familiarity modulates

effective connectivity during haptic shape perception. Neuroimage 49: 1991-2000.

Garoff-Eaton RJ, Slotnick SD, Schacter DL. 2006. Not all false memories are created equal: the neural basis of false recognition. Cereb Cortex 16: 1645-1652.

Goodale MA, Milner AD. 1992. Separate visual pathways for perception and action. Trends Neurosci 15: 20-25.

Gottfried JA, Smith APR, Rugg MD, Dolan RJ. 2004. Remembrance of odors past: Human olfactory cortex in cross-modal recognition memory. Neuron 42: 687-695.

Grill-Spector K, Kushnir T, Hendler T, Malach R. 2000. The dynamics of object-selective activation correlate with recognition performance in humans. Nat Neurosci 3: 837-843.

Gutchess A, Schacter D. 2012. The neural correlates of gist-based true and false recognition. Neuroimage 59: 3418-3426.

Heun R, Jessen F, Klose U, Erb M, Granath D, Grodd W. 2000. Responserelated fMRI analysis during encoding and retrieval revealed differences in cerebral activation by retrieval success. Psychiatry Res 99: 137-150.

Hofer A, Siedentopf CM, Ischenbeck A, Rettenbacher MA, Verius M, Golaszewski SM, Felber S, Flesichhacker WW. 2007. Neural substrates for episodic encoding and recognition of unfamiliar faces. Brain Cogn 63: 174-181.

Iidaka T, Harada T, Kawaguchi J, Sadat N. 2014. Neuroanatomical substrates involved in true and false memories for face. Neuroimage 62: 167-176.

Karanian JM, Slotnick SD. 2014. The cortical basis of true memory and false memory for motion. Neuropsychologia 54: 53-58.

Karanian JM, Slotnick SD. 2015. Memory for shape reactivates the lateral occipital complex. Brain Res 1603: 124-132.

Kourtzi Z, Kanwisher N. 2000. Cortical regions involved in perceiving object shape. J Neurosci 20: 3310-3318.

Lampinen JM, Neuschatz JS, Payne DG. 1998. Memory illusions and consciousness: Examining the phenomenology of true and false memories. Curr Psychol 16: 181-224.

Marchewka A, Brechmann A, Nowicka A, Jednoróg K, Scheich H, Grabowska A. 2008. False recognition of emotional stimuli is lateralized in the brain: an fMRI study. Neurobiol Learn Mem 90: 280-284.

Okado Y, Stark C. 2003. Neural processing associated with true and false retrieval. Cogn Affect Behav Neurosci 3: 323-334. 
Payne DG, Neuschatz JS, Lampinen JM, Lynn SJ. 1997. Compelling memory illusions: the qualitative characteristics of false memories. Curr Dir Psychol Sci 6: 56-60.

Roediger HL, McDermott KB. 1995. Creating false memories: Remembering words not presented in lists. J Exp Psychol Learn Mem Cogn 21: 803-814.

Sayres R, Grill-Spector K. 2008. Relating retinotopic and object-selective responses in human lateral occipital cortex. J Neurophysiol 100: 249-267.

Schacter DL, Norman KA, Koustaal W. 1998. The cognitive neuroscience of constructive memory. Annu Rev Psychol 49: 289-318.

Slotnick SD. 2005. Spatial working memory specific activity in dorsal prefrontal cortex? Disparate answers from fMRI $\beta$-weight and timecourse analysis. Cogn Neuropsychol 22: 905-920.

Slotnick SD. 2009a. Rapid retinotopic reactivation during spatial memory. Brain Res 1268: 97-111.

Slotnick SD. 2009b. Memory for color reactivates color processing region. Neuroreport 20: $1568-1571$.

Slotnick SD, Schacter DL. 2004. A sensory signature that distinguishes true from false memories. Nat Neurosci 7: 664-672.

Slotnick SD, Schacter DL. 2006. The nature of memory related activity in early visual areas. Neuropsychologia 44: 2874-2886.

Slotnick SD, Thakral PP. 2011. Memory for motion and spatial location is mediated by contralateral and ipsilateral motion processing cortex. Neuroimage 55: 794-800.

Slotnick SD, Yantis S. 2005. Common neural substrates for the control and effects of visual attention and perceptual bistability. Brain Res Cogn Brain Res 24: 97-108.
Slotnick SD, Thompson WL, Kosslyn SM. 2005. Visual mental imagery induces retinotopically organized activation of early visual areas. Cereb Cortex 15: 1570-1583.

Stark CE, Okado Y, Loftus EF. 2010. Imaging the reconstruction of true and false memories using sensory reactivation and the misinformation paradigms. Learn Mem 17: 485-488.

Thakral PP, Slotnick SD. 2014. Nonconscious memory for motion activates MT+. Neuroreport 25: 1326-1330.

Thakral PP, Slotnick SD, Schacter DL. 2013. Conscious processing during retrieval can occur in early and late visual regions. Neuropsychologia 51: $482-487$.

Thakral PP, Jacobs CM, Slotnick SD. 2017. An attention account of neural priming. Memory 25: 856-864.

Tong F. 2003. Primary visual cortex and visual awareness. Nat Rev Neurosci 4: 219-229.

Ungerleider LG, Mishkin M. 1982. Two cortical visual systems. In Analysis of visual behavior. MIT Press, Cambridge, MA.

Wheeler ME, Petersen SE, Buckner RL. 2000. Memory's echo: Vivid remembering reactivate sensory-specific cortex. Proc Natl Acad Sci 97: $11125-11129$.

Received April 14, 2017; accepted in revised form June 2, 2017. 


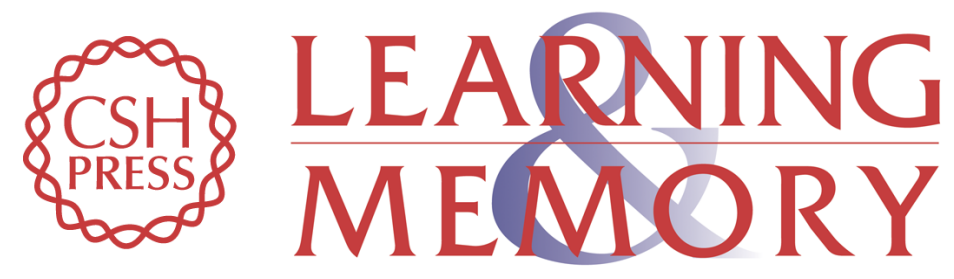

\section{False memories for shape activate the lateral occipital complex}

Jessica M. Karanian and Scott D. Slotnick

Learn. Mem. 2017, 24:

Access the most recent version at doi:10.1101/lm.045765.117

Supplemental http://learnmem.cshlp.org/content/suppl/2017/09/13/24.10.552.DC1

References This article cites 38 articles, 4 of which can be accessed free at: http://learnmem.cshlp.org/content/24/10/552.full.html\#ref-list-1

Creative This article is distributed exclusively by Cold Spring Harbor Laboratory Press for the Commons first 12 months after the full-issue publication date (see

License http://learnmem.cshlp.org/site/misc/terms.xhtml). After 12 months, it is available under a Creative Commons License (Attribution-NonCommercial 4.0 International), as described at http://creativecommons.org/licenses/by-nc/4.0/.

Email Alerting Receive free email alerts when new articles cite this article - sign up in the box at the Service top right corner of the article or click here. 